\title{
YÖNELIM METAFORLU DEYIMLERINN SINIFLANDIRILMASI
}

Muhammed Emin YILDIZLI ${ }^{1}$

Atıf/O: Yildızlı, Muhammed Emin (2017). Yönelim Metaforlu Deyimlerin Sinıflandırlmast. Hitit Üniversitesi Sosyal Bilimler Enstitüsü Dergisi, Yıl 10, Sayı 2, Aralık 2017, ss. 1489-1498

Özet: İnsanin dünyadaki fiziksel konumuna göre şekillendiği düşünülen yönelim metaforlarl, Türkiye Türkçesindeki deyimler incelendiğinde genel yönelim metaforları tasniflerinden farklı bir özellik göstermektedir. Bu özellik söylem ve anlamin iki yönlü olarak ortaya çıtığı ifadelerde kendisini göstermiştir. Çalışmada Türkçe deyimlerdeki yönelim metaforlarının bu yeni tespit ışığında örnekleriyle beraber sinıflandırılması amaçlanmıştır.

Anahtar Kelimeler: Metafor, Yönelim Metaforlan, Deyim, Deyimlerde Yönelim Metaforlar, Metafor Siniflandirmasi

\section{Classification of Orientation Metaphorical in Idioms}

Citation/O: Ylldizl, Muhammed Emin (2017). Classification of Orientation Metaphorical in Idioms, Hitit University Journal of Social Sciences Institute, Year 10, Issue 2, December 2017, pp.1489-1498

Abstract: The orientation metaphors, which are thought to be shaped according to the physical position of human in the world, show a different characteristic from the general orientation metaphors classification when the Turkey Turkish terms are examined.This feature is the expression of discourse and meaning that emerged in two directions. In this study, it is aimed to classify the metaphors of orientations in Turkish idioms with this new determination.

Keywords: Metaphors, Orientational Metaphors, Idiom, Metaphors of Orientation in Idioms, Metaphor Classification

Makale Gelis Tarihi: 10.10.2017/ Makale Kabul Tarihi: 23.10.2017

${ }^{1}$ Dr., Nevşehir Hacı Bektaş Veli Üniversitesi, Fen- Edebiyat Fakültesi Türk Dili ve Edebiyatı Bölümü,

eminyildizli@gmail.com 


\section{GİRIŞ}

Türkçenin şimdilik en eski yazılı metinleri arasında olan Kültigin abidesinin doğu yüzünün 1.satırı "Üstte mavi gök, altta yağız yer kılındıkta, ikisi arasında insanoğlu yaratılmış” (Ergin, 2002: 9) şeklinde başlarken, yağız yer ve kutsal gök arasındaki insan, doğduğu andan ölümüne kadar her zaman göğe doğru bir yönelim içerisinde olmuştur. Çünkü tüm kutsallık, bilgi, erdem, mutluluk, günlük yaşantısını idame ettirmek için gerekli su vb. neredeyse insan hayatının içerisindeki her şey bu inanç ve kültür sistemiyle şekillenmiştir. ${ }^{2}$

Birbirlerinin tamamlayıcısı ve var oluş sebebi olan kültür ve dil kendi sistemlerini bir bütün halinde bir sonraki nesillere ve yüzyıllar ötesine taşıyabilme adına çeşitli anlatım yolları geliştirmişlerdir. Bu anlatım yolları; şiirler, destanlar, halk hikâyeleri, masallar, atasözleri, deyimler vb. şekillerde ortaya çıkarken, anlatım yollarını daha sanatlı, daha akılda kalıcı, daha etkileyici kılmak için sistematik ifadeler geliştirmişlerdir. Bu ifade yolları ise tamamen ortaya çıktığı kültürün ve dilin bir ürünü olarak halk anlatılarında veya söylemlerinde yerini almıştır. Bunlardan bir tanesi de metaforlardır. Metaforlar, insanın algıladığı her şeyi, dünyada yolumuzu bulma tarzımızı, diğer insanlarla ilişki kurma biçimimizi, tecrübelerimizi ve bunların bilişimizdeki düşünme sürecini aktarmamızdaki "kavram" alanlarıdır (Lakoff, Johnson, 2005: 25-28).

Bu noktada "kavram" tanımının verilmesi, konunun anlaş1lırlığı açısından önem taşımaktadır. "Bir şeyin, bir nesnenin zihindeki ve zihne ait tasarımı; soyut düşünme faaliyetinde kullanılan ve belli bir somutluk ya da soyutluk derecesi sergileyen bir düşünce, fikir ya da ide. Soyutlama yoluyla elde edilen zihinsel tasavvur olarak kavram, ortak özellikleri paylaşan bir nesneler kompleksinin veya söz konusu nesnelerin paylaştığı ortak özellik ya da niteliklerin psikolojik ya da zihinsel temsili ya da tasarımına karşılık gelir. Başka bir deyişle, bir terimin anlamı ve dolayısıyla düşüncenin, bir terimin konuşma ya da söylemin en küçük birimi olması gibi, en küçük ve en temel birimi olan kavram, bir sınıfın üyeleri ya da sınıfın kendisi için kullanılan isim; betimleyici bir özellik ya da bağıntıya gönderimde bulunan bir terim olmak durumundadır. Tıpkı tümce oluşturmak için terimlerin bir araya getirilmesi

\footnotetext{
${ }^{2}$ Kainatın bütün tezahürlerini gök ve yir-sub/v'un (yer-su: yeryüzü) temsil ettiği birbirine zıt, fakat birbirini tamamlayan iki evrensel 'nefes'ten oluşmuş olarak kabul eden sistem, proto-Türk ve Türklerin en eski, belki de öz kozmolojisiydi. (Esin, 2001: 19)
} 
gibi, kavramlar da, önermeler oluşturmak ya da tam ve eksiksiz düşünceler meydana getirmek için bir araya getirilir (Cevizci, 2005: 988).”

$\mathrm{Bu}$ tanım çerçevesinde metaforlar, insan bilişindeki "şey"lerin daha etkili bir anlatımla başka bir "şey" üzerinde yeni ve geçici kavram alanları oluşmasını sağlamaktadır. Biliş bunu yaparken kendi kültüründen, ana dilinin kelime ve anlam hazinesinden faydalanmaktadır. Daha geniş ifadeyle Yıldızlı metafor tanımını şu şekilde vermektedir: "Bir milletin günlük yaşantısında karşılaştığ durumları, nesneleri, kendi kültürel zihinleri içerisinde anlamlandırıp, bu anlamlandırmaların günlük yaşantılarına, dillerindeki kelimelere ve cümlelere yeni bir anlam olarak yansıması sonucu oluşan algılama biçimidir diyebiliriz. Metaforu; benzetme yoluyla yapılan çağrışımlarla bir ifadeyi başka bir ifadeyle (benzer yönler öne çıkarılmalı) üçüncü boyut anlamlandırma olayı olarak da düşünmekteyiz (Yıldızlı, 2011: 15).”

Bu üçüncü boyut anlamlandırma "Zamanımı harcıyorsun. Sana harcayacak vaktim yok. Bu patlak lastik bir saatime mâl oldu." gibi benzer ifadelerle "Zaman Paradır" şeklinde metaforlar oluşturmaktadırlar (Lakoff, Johnson: 2005: 30). ${ }^{3}$

Lakoff ve Johnson'un yap1 metaforları olarak adlandırdığı metaforlar, kavramın metaforik ifadeyle yeni bir yapıya dönüştüğü durumlardır (Lakoff, Johnson: 2005: 36). Lakoff ve Johnson, bu çalışmanın konusunu oluşturan yönelim metaforları için ise "Kavramı diğerine göre yapıya kavuşturmayan, bunun yerine bütün bir kavramlar sistemini diğer kavramlar sistemine göre organize eden metaforlardır." şeklinde tanımlarlar (Lakoff, Johnson: 2005: 36).

Yönelim metaforlarını uzay-mekân ilişkisi içerisinde inceleyen araştırmacılar. İnsanın dünyadaki fiziksel bulunuşluğunun yönelim metaforlarını oluşturduğunu söylemektedirler. Yukarı-aşağı, içeri- dışarı, ön-arka, beri-öte, derin-satıh, merkez-çevre şeklinde gelişen yönelim metaforları insanın bedeni ve çevresi ile olan ilişkisi neticesinde ortaya çıkmaktadır (Lakoff, Johnson: 2005: 36-37). "Dünya bir uzam, bir boşluk ve büyük bir mekândır. İnsanlar çok büyük bu mekân içinde yaşamaya çalışırlarken, boşluktaki davranışlarını gök ve yere göre düzenlemeye çalışmışlardır. Hareketler ya yerle göğe

\footnotetext{
${ }^{3}$ Metafor çalışmaları için bakınız: Lakoff, G. Johnson, M. (2005). Metaforlar Hayat, Anlam ve Dil (Çev:Gökhan Yavuz Demir). İstanbul: Paradigma; ÇETINKAYA, Bayram (2006). Türkiye Türkçesinde Mutluluk ve Üzüntü Göstergeleri. Doktora Tezi. Gazi Üniversitesi Sosyal Bilimler Enstitüsü. ERDEM, Melek (2003). Türkmen Türkçesinde Metaforlar. Ankara: Köksav. KEMAL, Mağfiret (2003). Buddhist Türk Çevresi Eserlerinde Metafor. Doktora Tezi, Ankara Üniversitesi Sosyal Bilimler Enstitüsü.
} 
paraleldir, yataydır ve ya yerle göğe zıt yöndedir, dikeydir. Paralellik içinde ileri-geri, ön-arka, sağ-sol... gibi yönler yer alırken, dikeylik içinde yukarıaşağ1, üst-alt... gibi yönler bulunmaktadır (Kemal Yunusoğlu, 2015:1633).”

Buna benzer. tanımlardan hareketle yönelim metaforlarının tasnifinde ve açıklanmasında araştırmacılar Lakoff ve Johnson'un fiziksel ve kültürel tecrübelere dayalı anlatımlarını kendi çalışmalarında kullanmışlardır. ${ }^{4}$

Araştırmacılara göre;

Mutlu olan yukarıda (Ayaklarımı yerden kesiyor), kederli olan aşağıdadır. (Dünyam başıma yıkıldı).

Bilinçli olan yukarıda (Uyandım, ayaktayım), bilinçsiz olan aşağıdadır (Uykuya daldi) .

Sağlık ve hayat yukarıda (Çok hastaydı yeni kalkabildi), hayat ve ölüm aşağıdadır (Çok yaşlandı, iyice elden ayaktan düştü).

Kontrol yahut güç sahibi olma yukarıda (Gücünün zirvesinde), kontrole yahut güce maruz kalma aşağıdadır (Ona işim düştü).

Çok olan yukarıda (Satışlarını yükseltmeyi başard1), az olan aşağıdadır (Dara düştü).

Öngörülebilir bir gelecekteki olaylar yukarıda veya ileridedir (Şirketimiz yükselen bir değer olabilir).

Yüksek statü yukarıda (El üstünde bir hayat sürdü), düşük statü aşağıdadır (Onun adı batsin).

İyi olan yukarıda (Başımın üstünde yeri var), kötü olan aşağıdadır (Yaptığından dolayı işleri ters düştü).

Erdemli olan yukarıda (Başı dik bir insan), erdemsiz olan aşağıdadır ( Çok aşağılık bir adam).

Rasyonel olan yukarıda (Gerçekler gün yüzüne çıkacak), duygusal olan aşağıdadır (Anlattıklarının altında ezildi) (Lakoff, Johnson: 2005: 37-39).

\footnotetext{
${ }^{4}$ Kemal Yunusoğlu, Mağfiret. (2015). Yönelim Metaforları ve Kültürel Temelleri. Turkish Studies. Volume 10/8 Spring 2015, p. 1627-1642.Sarı, Ceyhun.(2016). Deyimlerde Așağı/Yukarı Yönelim Metaforu. Uluslararası Sosyal Araştırmalar Dergisi Cilt: 9 Sayı: 44 Volume: 9 Issue: 44 212-216. Gen, Sila. (2012). Tahsin Yücel'in Salaklık Üstüne Deneme'sinde Yönelim Metaforları. Mine Mengi Adına Türkoloji Sempozyumu Bildirileri.
} 
Metafor konusunda yapılan çalışmalar ve verilen örnekler incelendiğinde görülmüştür ki, yönelim metaforlarının bulunduğu ifadelerdeki anlam olumlu yönde olduğunda metafor yukarı doğru bir seyir içerisindeyken, ifadelerdeki anlam olumsuz olduğunda ise yönelim aşağı doğru bir hareket içerisinde olmaktadır. Çalışmalarda bu durumun insanın hem kültürel hem de tecrübe temelli olarak bu ifade tarzlarını geliştirdiği ve bu ifadelerin kültürden kültüre değişim gösterebileceği fakat bu değişimin çok spesifik olmayacağ düşünülmüştür. Sebep olarak ise insanın dünyadaki fiziksel durumunun tüm insanlık için aynı olduğu görüşüyle de bu açıklama desteklenmeye çalışılmıştır.

Türkiye Türkçesindeki deyimler 5 bu açıklamalar 1şığında incelendiğinde görülmüştür ki, deyimler büyük oranda yönelim metaforlarının genel kabullerine uygun bir şekilde oluşmuştur. İnsanda olumlu duygular oluşturan metaforlar olumlu ifade şekilleriyle yukarı, insanda olumsuz duygular oluşturan metaforlar olumsuz ifade şekilleriyle aşağı doğru bir yönelim içerisinde olmuşlardır. Fakat Türkiye Türkçesinin söylem ve anlam gücünün, deyimlerde de kendisini gösterdiği ve bu klasik yönelim metaforları tasnifine aykırı durumlar meydana getirdiği görülmüştür. Bu durumu konunun anlaşılırlığı açısından, metafor açıklamaları üzerinden birkaç örnekle netleştirmek gerekmektedir.

Deyim: Gün ışı̆̆ına çıkmak.

Metafor Yönü: Anlamsal ve söylemsel olarak deyimdeki yönelim yukarı doğrudur.

Metafor Açıklaması: Deyim yukarı doğru yönelimini "çıkmak" fiiliyle verirken aynı zamanda anlam olarak da muhatabına olumlu bir duygu vermektedir.

Deyim: Başı dara düşmek.

Metafor Yönü: Anlamsal ve söylemsel olarak deyimdeki yönelim aşağ1 doğrudur.

\footnotetext{
${ }^{5}$ Bir kavram1, bi durumu, ya cekici bir anlatımla ya da özel bir yapı icinde belirten ve çoicinde belirten ve cindan ayn bir anlamı bulunan kalıplalunan özcük toplulukalmten tümce (Aksoy, 1988:52)..

Deyimler iki veya daha çok kelimeden kurulmuş, asıl anlamlarından uzaklaşarakyeni anlamlar kazanmış kalıplaşmış söz öbekleridir. Deyimler yazılı ve sözlü anlatımıngücünü artırarak onu daha etkili ve güzel hale getiren dil öbekleridir (Hirik, 2010:142).
} 
Metafor Açıklaması: Deyim aşağı doğru olan yönelimini düşmek eylemiyle sağlarken sıkıntı ve kedere maruz kalmak anlamıla muhatabına olumsuz, kötü hissettiren bir duygu vermektedir.

Deyim: Havaya gitmek.

Metafor Yönü: Anlamsal ve söylemsel olarak farklı yönlü bir metafor olmakla birlikte metaforun yönü aşağı doğrudur.

Metafor Açıklaması: Söylem ve anlam olarak farklı yönlerde metafor ortaya çıkmıştır. Metaforlar uyandırdığı duygu noktasında değerlendirildiğinde buradaki metafor anlamsal olarak aşağı doğru bir yönelim içerisindeyken, söylemde bu ifade normal şartlar altında yukarı doğru yönelime sebep olması gereken "Hava" kelimesiyle birlikte bir zıtlık tertip etmiştir. Bu düzenleyişle birlikte metafor, anlamsal ve söylemsel olarak iki yönlü bir metafor ortaya çıkmıştır.

Lakoff ve Johnson bu vb. durumlar için, metaforların tecrübe temelli olmasını ve bu tecrübe temellerine tam olarak haiz olamamanın, bu tarz yapıların nasıl ortaya çıktığının açıklanması hususunda net bir fikrin ortaya koyulamayacağını ifade etmektedirler (Lakoff, Johnson: 2005: 42-43). Bu açıklamayla birlikte bu yapıların nasıl ve niçin ortaya çıktığından ziyade, bu yapıların dilin kullanım sınırları içerisinde dili nasıl zenginleştirdiğini ve dilin ifade yeteneğini nasıl geliştirdiğini göstermesi açısından incelenmesi önemli görülmektedir.

Gün 1şığına çıkmak ve başı dara düşmek deyimleri klasik metafor tasniflerine uygun birer örnek olarak Türkçedeki varlığını devam ettirmektedir. Bunun yanında bu metafor tasnifleri içerisinde yerini almayan ve "havaya gitmek" deyiminde görülen durum Türkçede bir çok deyimde tespit edilmiştir.

Bu çalışma kapsamında genel olarak yönelim metaforlarının tasnifi açısından Türkiye Türkçesindeki farklılığın tespit edilmesiyle yeni bir sınıflandırmanın yapılması gerekli görülmüştür. Bu tasnif doğrultusunda yapılacak olan çalışma Türkçenin ifade gücünü ve ifade çeşitliliğini göstermesi ayrıca metaforların ve söylemlerin dilden dile ve kültürden kültüre değişiminin görülmesi açısından önem arz etmektedir.

$\mathrm{Bu}$ bağlamda çalışmanın inceleme kısmında; insanda olumlu duygular oluşturan ve yönelimi yukarı doğru metaforlar ile insanda olumsuz duygular oluşturan ve yönelimi aşağı doğru olan metaforlar "Metaforik Olarak Anlamı 
ve Söylemi Aynı Yönlü Deyimler” şeklinde, insanda oluşturduğu duygu açısından söylemsel ve anlamsal olarak farklı yönde duygusal ifadeleri içerisinde barından metaforlar "Metaforik Olarak Anlamı ve Söylemi İki Yönlü Deyimler" şeklinde değerlendirilecektir. Çalışma kapsaminda Ömer Asım Aksoy’un “Atasözleri ve Deyimler Sözlüğü II Deyimler Sözlüğü” isimli çalışması incelenmiş olup sınıflandırma için yeterli derecede örneğin makalede işlenmesine olanak sağlanmıştır. Anlamsal ve söylemsel olarak aynı yönlü metaforlar başlığı altında tasnif edilen "Deyimlerde Olumlu ve Yukarı Doğru Metaforlar” ile “Deyimlerde Olumsuz ve Aşağı Doğru Metaforlar” ve Türkçenin anlam/söylem gücünün farkını ortaya koyduğu düşünülen, anlamsal ve söylemsel olarak iki yönlü metaforlar başlı̆̆ altında, tespit edilebilen bütün deyimler çalışma kapsamında verilmeye çalışılmıştır.

\section{Metaforik Olarak Anlamı ve Söylemi Aynı Yönlü Deyimler}

Dil bir iletişim aracı olarak düşünüldüğünde, dildeki unsurlar kelime ve o kelimenin anlamı/anlamları ile muhatabının bilişinde yer bulur. Muhatabın bilişinde yer bulan ifadeler kültürel ve kişisel tecrübelerle anlamlandırılır. Metaforlarda da bu durum geçerlidir. "Metaforik Olarak Anlamı ve Söylemi Aynı Yönlü Deyimler" söylem ve anlamın muhatabında aynı yönde duygular uyandırdığ 1 deyimlerdir.

\section{A. Deyimlerde Olumlu, Yukarı Doğru Yönelim Metaforları}

Ağzı kulaklarına varmak, aklı başında olmak, altından kalkmak, arabasını düze çıkarmak, ayağa kalkmak, ayağı yerden kesilmek, ayağı (ayakları) yere değmemek, el üstünde tutulmak, ayakları yere değmemek, göğsü kabarmak, göklere çıkarmak (uçurmak), gün ışığına çıkmak, içi kabarmak.

\section{B. Deyimlerde Olumsuz, Aşağı Doğru Yönelim Metaforları}

Alaşağı etmek, açmaza düşmek, adı batmak, Allah'ın binasını yıkmak, atlıyı atından indirmek, ayağına kapanmak, ayağına (ayaklarına) kara su inmek, ayağının altına almak, ayağının altına karpuz kabuğu koymak, ayağının altında olmak, ayağıyla tuzağa düşmek, ayak altında kalmak, , baş aşağ gitmek, başı dara düşmek, başına yıkmak, başından kaynar sular dökülmek, başının (canınin) derdine düşmek, birbirine düşmek, boş düşmek, boyu devrilesi (devrilesice), burnu düşmek, çam devirmek, çaptan düşmek, çenesi düşük (çürük), dağlara düşmek, dara düşmek, derdine düşmek, derinlere dalmak, dile (dillere) düşmek, dünya başına yıkılmak, dünya yıkılsa umurunda değil, eline ayağına düşmek (sarılmak), ev yıkmak, gölge düşmek, gölge düşürmek, gönül 
indirmek, götüne mi düşmüş, gözden düşmek, içine (yüreğine) ateş düşmek, içine atmak, kapana düşmek (tutulmak), kendi derdine düşmek, küçük düşmek, mahkemeye düşmek, meydana düşmek, ocağına düşmek, ortaya (ortalığa) düşmek, paçası düşük, pusuya düşmek, yerden yere vurmak, yerin dibine geçmek.

\section{Metaforik Olarak Anlamı ve Söylemi İki Yönlü Deyimler}

Deyimlerdeki yönelim metaforlarına dair bir tasnif denemesi olan bu araştırmada, yönelim metaforları ile ilgili diğer çalışmalardan farklı olarak, söylem ve anlamın iki yönde geliştiği metaforik ifadeler "Metaforik Olarak Anlamı ve Söylemi İki Yönlü Deyimler” başlığı altında sınıflandırılmıştır.

Açığa çıkarılmak, adamına düşmek, adı çıkmak, adı çıkmış dokuza, inmez sekize, ăgzı havada, aklına düşmek, ateşi düşmek, başına çıkmak, bokunu çıkarmak, boyun bir karış uzadı, borç gırtlağına çıkmak, boşa çıkmak, burnu büyümek, burnu havada (olmak), burnu Kaf dağında (olmak), cinleri ayağa kalkmak, cinleri başına toplanmak, cini tepesine çıkmak, çizmeden yukarı çıkmak, dağa çıkmak, dağa kaldırmak, dünür düşmek, gözü yükseklerde olmak, havaya gitmek, içi kalkmak, içini dökmek, kan çıkmak, kapağı (bir yere) atmak.

\section{SONUÇ}

Metaforlar geçici anlam aktarımları olarak düşünüldüğünde, metaforun kavramsal yapısının açıklanmasında yine metaforik olarak "empati" kelimesinin kullanılması düşünülebilir. Bu durum şu şekilde örneklenebilir: Bir şahsa "Kendini Ahmet'in yerine koy." şeklinde bir cümle kurulduğunda, şahıs geçici bir süre için kendisini Ahmet'le özdeşleştirir ve Ahmet’in özelliklerinin belli bir süreliğine kendisine yansıdığını düşünür. Ahmet gibi düşünüp onun gibi hareket etmeye çalışır. Bu geçici bir durumdur ve Ahmet'in hissettiklerini kavradıktan sonra şahıs bu hâli sonlandırır. Metaforik ifadeler de bu şekilde bir kelimenin veya duygunun geçici olarak başka bir kelime ve o kelimenin anlam yönüyle empati kurmasıdır. Kısacası metaforalar kelime ve anlam empatisi olarak da açıklanabilir. Böylelikle ifadeler, basmakalıp, sıkıcı ve tekdüze bir anlatımdan sıyrılıp belli duygular taşıyarak, etkileyici bir hâl alırlar. Bu durum metaforların oluştuğu dilin anlam derinliğiyle ve kültürel birikimiyle paralel bir şekilde zenginleşir. Dilin ifade yeteneği ve gücü artar. 
Dilin ifade yeteneğini ve anlam zenginliğini arttırdığı araştırmalarda tespit edilen metaforlar, Türkiye Türkçesi özelinde deyimlerde ve sınırlı bir şekilde bu çalışmayla, yönelim metaforları kapsamında incelenmiştir. Türkçe dünyanın ortak kültürüne ait aşağı/yukarı yönelimini, olumlu/olumsuz duygularla birlikte metaforik olarak ifade etmektedir. Fakat Türkçe geliştirmiş olduğu anlam yapıları ve ifade şekilleriyle söylem olarak olumlu bir yapıyı anlam dünyasında olumsuz bir duyguyla veya söylem olarak olumsuz bir duyguyu anlam olarak olumlu bir duyguyla karş1layabilecek zenginlikte ifade yeteneğine sahiptir. Bu çalışmayla birlikte Türkçe deyimlerdeki yönelim metaforlu yapıların tasnifi ve incelenmesinin dışında Türkçenin ifade zenginliğinin de ortaya çıkarılmasına olanak sağlanmıştır.

\section{KAYNAKÇA}

AKSOY, Ömer Asım. (1988), Atasözleri ve Deyimler Sözlüğü II Deyimler Sözlüğü. İnkılap, İstanbul.

CEVİZCI, Ahmet. (2005), Paradigma Felsefe Sözlüğü. Paradigma, İstanbul.

ERGIN, Muharrem. (2002), Orhun Abideleri. Boğaziçi Yayınları, İstanbul.

ESIN, Emel. (2001), Türk Kozmolojisinde Giriș. Kabalcı, İstanbul.

GEN, Sila. (2012), "Tahsin Yücel'in Salaklık Üstüne Deneme'sinde Yönelim Metaforları", Mine Mengi Adına Türkoloji Sempozyumu Bildirileri 20-22 Ekim 2011. Adana, Çukurova Üniversitesi Yayınları.

HİİK, Erkan. (2010), Türkiye Türkçesinde Olumsuzluk Eki. Kırıkkale Üniversitesi Sosyal Bilimler Enstitüsü Yayımlanmamış Yüksek Lisans Tezi, Kırıkkale.

KEMAL YUNUSOĞLU, Mağfiret. (2015), "Yönelim Metaforları ve Kültürel Temelleri", TurkishStudies. Volume 10/8 Spring 2015, p. 1627-1642.

LAKOFF, George, Johnson Mark. (2005), Metaforlar Hayat, Anlam ve Dill(Gökhan Yavuz Demir, Çev.). Paradigma, İstanbul.

SARI, Ceyhun.(2016), "Deyimlerde Aşağı/Yukarı Yönelim Metaforu”, Uluslararası Sosyal Arasstırmalar Dergisi Cilt: 9 Sayl: 44 Volume: 9 Issue: 44 212-216.

YILDIZLI, M. Emin. (2011), Kutadgu Biligte Dünya Metaforu, Hacettepe Üniversitesi Sosyal Bilimler Enstitüsü Yayımlanmamış Yüksek Lisans Tezi, Ankara. 
